\title{
Internal auditory canal hypoplasia associated with bilateral vestibulocochlear nerve aplasia and deviant facial nerve course: A case report and MRI findings
}

\author{
Luiz Ricardo Araújo Uchôa ${ }^{1}$, Licia Pacheco Luna ${ }^{1,2 *}$, Luis Arthur Brasil Gadelha Farias ${ }^{1}$, Debora \\ Lilian Nascimento Lima ${ }^{3}$, Pablo Picasso de Araujo Coimbra ${ }^{1}$ \\ 1. Radiology Department, Fortaleza General Hospital (HGF), Fortaleza, Ceará, Brazil \\ 2. Department of Radiology, Division of Neuroradiology, Johns Hopkins Hospital, Baltimore, USA \\ 3. Otorhinolaryngology Department, Fortaleza General Hospital (HGF), Fortaleza, Ceará, Brazil \\ * Correspondence: Licia Pacheco Luna, Department of Radiology, Division of Neuroradiology, Johns Hopkins Hospital. Postal Mail: 600 \\ N Wolfe Street Phipps B100F, 21287, Baltimore, USA \\ (入lluna6@jhmi.edu)
}

Radiology Case. 2021 May; 15(5):17-23 :: $\quad$ DOI: 10.3941/jrcr.v15i5.3912

\begin{abstract}
The evaluation of internal auditory canals and cochlea has gained significant importance due to the increasing number of cochlear implantations worldwide. This region's anatomical study is essential for cochlear implant surgery using magnetic resonance imaging as the method of choice. We report a case of a 6-year-old male patient diagnosed with a rare bilateral malformation of the internal auditory canals associated with an aberrant course of the facial nerve and vestibulocochlear nerve aplasia. This report raises the importance of identifying this rare malformation for appropriate management and reinforces awareness of possible complications.
\end{abstract}

\section{CASE REPORT}

\section{CASE REPORT}

A 6-year-old male patient with marked bilateral congenital sensorineural hearing loss (SNHL) presented to the outpatient clinic for evaluation of possible cochlear implantation.

The neurological and otorhinolaryngological exams showed abnormal language development and difficulties with social interaction. Absent otoacoustic emissions and brainstem auditory evoked potentials were also noted bilaterally. He tried hearing aids without improvement. No other neurodevelopmental or neurological abnormalities were observed, including spared facial nerves (FN) function.
Magnetic resonance imaging (MRI) demonstrated bilateral stenosis of the internal auditory canals (IAC) and the absence of the cisternal and intracanalicular fibers of the vestibulocochlear nerve, indicating agenesis (Figures 1 and 2). An stenotic IAC was considered if it measured less than $2 \mathrm{~mm}$ in the coronal plane (Figure 1). An associated anomalous intracranial course of the FN was observed bilaterally (Figures 3 and 4).

Due to patient's inner ear malformations, including cochlear nerve aplasia, cochlear implantation was contraindicated. 


\section{DISCUSSION}

\section{Etiology \& Demographics:}

The aberrant FN is not rare in patients with congenital anomaly of the middle ear. In their series of 227 subjects with middle ear anomalies, Hao and colleagues found aberration of FN in $32 \%$ of patients, with facial nerve displacement as the most commonly observed malformation [1]. The aberrant FN may cause blockage of the oval window and cross over other structures [1]. The majority of patients with FN anomaly do not present with clinical symptoms. However, when it is present, it is usually due to conductive hearing loss from an accompanying ossicular chain abnormality $[1,2]$.

The prevalence of congenital sensorineural hearing loss (SNHL) is approximately 1-6 per 1,000 live births [3,4]. Hypoplasia of the IAC is a rare malformation, believed to be due to agenesis of the vestibulocochlear nerve (VCN) [5]. When this association is present and there is no dysfunction of the FN, it may course posteroinferiorly to the trigeminal nerve [5].

Rarely, the aberrant FN may run into a separate canal, usually preserving normal function [6]. Moreover, an aberrant anterior course of the FN often represents the smallest distance to the facial musculature [7].

\section{Clinical \& Imaging findings:}

The evaluation of IAC and cochlea has gained great importance due to the increasing number of cochlear implantations throughout the world [6]. MRI is the method of choice to investigate pathologies in this region, both congenital and acquired [8].

The diagnosis of IAC hypoplasia and $\mathrm{VCN}$ agenesis associated with an abnormal FN course is essential for the cochlear implant preoperative evaluation. While FN course variations commonly occur in the middle ear, these are rare in the intratemporal and intracranial compartments [9]. According to Wu C. et al., it is rare to find an anomalous course of FN in patients without abnormalities in the external ear or tympanic membrane, as presented in the case [11]. The diagnosis of IAC malformations with or without variances in the FN and bilateral VCN agenesis are usually made by MRI $[3,4]$. Moreover, computed tomography (CT) of the temporal bone can also evaluate this anatomic region $[9,12]$. De Foer B. et al. highlights the importance of axial and parasagittal reformations of heavily 3D T2-weighted sequences for the assessment of aplasia or hypoplasia of the VCN [6].

Unfamiliarity with the FN aberrant course may lead to surgical complications, including inadvertent injuries [10, 13]. In our case, there was no dysfunction of the $\mathrm{FN}$, despite its rare abnormal course. On MRI, an anomalous intracranial course of the FN was observed bilaterally. The cisternal segment was dislocated inferior to the trigeminal nerve, running towards the Gasserian ganglion and taking a sharp lateral turn into a minute canal, reaching the geniculate ganglion (Fig. 1-3).

\section{Treatment \& Prognosis:}

Cochlear nerve aplasia and other malformations of the IAC constitute contraindications for cochlear implantations. In such cases, an auditory brainstem implant (ABI) may be suggested. An ABI is a device placed directly on the cochlear nuclei in the fourth ventricle through a retrosigmoidtransmeatal approach [14-16]. This type of implant is a more recent auditory rehabilitation technique, usually performed in patients with neurofibromatosis type 2 (NF2) suffering from bilateral hearing loss due to disruption of the VCN [7]. There are only a few cases of patients with cochlear nerve aplasia undergoing this procedure [17]. Thus, further studies are needed to evaluate the efficacy of this technique in this subgroup of patients.

\section{Differential Diagnoses:}

\section{ABERRANT FACIAL NERVE}

\section{Moebius syndrome}

Moebius syndrome is a rare congenital anomaly characterized by sixth and seventh cranial nerve palsies. Other abnormalities involving the limbs, chest wall, and spine may also be seen. Radiologically, the sixth and seventh cranial nerve nuclei are absent, as seen by flattening of the fourth ventricle and pontine hypoplasia. There may be cerebellar hypoplasia, calcification of the pons in the region of the abducens nerve, and absence of the middle cerebellar peduncles.

\section{Aberrant facial nerve (FN) canal}

The FN arises inferiorly and laterally from Meckel's cave, then courses through the petrous bone to the IAC fundus. Distally there is normal morphology of the remaining labyrinthine, tympanic, and descending mastoid facial nerve segments.

\section{Hypoplastic facial nerve canal}

The labyrinthine facial nerve is reduced in caliber. It may be isolated or associated with the other segments' hypoplasia and can be often seen in inner ear dysplasia.

\section{Hypoplastic internal auditory canal and a separate facial nerve canal}

The facial nerve may lie anterosuperior to the IAC, sometimes seen in association with inner ear dysplasia.

\section{TEACHING POINT}

Hypoplasia of the IAC is associated with bilateral agenesis of the VCN. Anomalous FN course is a rare and important auditory system abnormality. Aberrant intracranial FN course should be investigated in patients with hypoplasia of the internal auditory canal and normal FN function.

A potential alternative treatment for children with an absent or deficient eighth cranial nerve is auditory brainstem implantation. The aberrant FN course may increase the risk of complications during this and other otorhinolaryngological procedures. 


\section{REFERENCES}

1. Hao J, Xu L, Li S, Fu X, Zhao S. Classification of facial nerve aberration in congenital malformation of middle ear: Implications for surgery of hearing restoration. J Otol 2018, 13(4):122-127. PMID: 30671087

2. Cho J, Choi N, Hong SH, Moon IJ. Deviant facial nerve course in the middle ear cavity. Braz J Otorhinolaryngol 2015, 81:681-683. PMID: 26410382

3. Santos S, Domínguez MJ, Cervera J, Suárez A, Bueno A, Bartolomé M, López R. Hearing loss and enlarged internal auditory canal in children. Acta Otorrinolaringol 2014, 65(2):93-101. PMID: 24534420

4. White KR, Vohr BR, Maxon AB, Behrens TR, McPherson MG, Mauk GW. Screening all newborns for hearing loss using transient evoked otoacoustic emissions. International Journal of Pediatric Otorhinolaryngology 1994, 29(3):203-217. PMID: 8056504

5. Giesemann AM, Neuburger J, Lanfermann H, Goetz F. Aberrant course of the intracranial facial nerve in cases of atresia of the internal auditory canal (IAC). Neuroradiology. 2011, 53:681-687. PMID: 21448638

6. De Foer B, Kenis C, Van Melkebeke D, Vercruysse JP, Somers T, Pouillon M, Offeciers E, Casselman JW. Pathology of the vestibulocochlear nerve. European Journal of Radiology 2010, 74(2):349-358. PMID: 20347243

7. Colleti L, Shannon R, Colleti V. Auditory brainstem implants for neurofibromatosis type 2. Curr Opin Otolaryngol Head Neck Surg 2012, 20:353-357. PMID: 22886036

8. Casselman JW, Offeciers FE, Govaerts PJ, Kuhweide R, Geldof H, Somers T, D'Hont G. Aplasia and hypoplasia of the vestibulocochlear nerve: diagnosis with MR imaging. Radiology 1997, 202(3):773-781. PMID: 9051033

9. Glastonbury CM, Fischbein NJ, Harnsberger HR, Dillon WP, Kertesz TR. Congenital bifurcation of the intratemporal facial nerve. American Journal of Neuroradiology 2003, 24(7):1334-1337. PMID: 12917123

10. Sataloff RT. Embryology of the facial nerve and its clinical applications. Laryngoscope 1990, 100(9): 969-984. PMID: 2395407

11. Wu C, Ng S, Liu T. Facial Nerve Overlying Stapes Footplate as a Cause of Conductive Hearing Loss. Otology and Neurotology 2008, 29:1204. PMID: 18277310

12. Song JJ, Park JH, Jang JH, Lee JH, Oh SH, Chang SO, Kim CS. Facial nerve aberrations encountered during cochlear implantation. Acta Otolaryngologica 2012, 132: 788-794. PMID: 22668344

13. Al-Mazrou KA, Alorainy IA, Al-Dousary SH, Richardson MA. Facial nerve anomalies in association with congenital hearing loss. International Journal of Pediatric Otorhinolaryngology 2003, 67:1347-1353. PMID: 14643480
14. Govaerts PJ, Casselman J, Daemers K, De Beukelaer C, Yperman M, De Ceulaer G. Cochlear implants in aplasia and hypoplasia of the cochleovestibular nerve. Otology and Neurotology 2003, 6:887-891. PMID: 14600469

15. Nevison B, Laszig R, Sollmann WP, Lenarz T, Sterkers O, Ramsden R, Fraysse B, Manrique M, Rask-Andersen H, Garcia-Ibanez E, Colletti V, von Wallenberg E. Results from a European clinical investigation of the nucleus multichannel auditory brainstem implant. Ear Hear 2002, 23(3):170 - 183. PMID: 12072610

16. Colletti V, Carner M, Miorelli V, Guida M, Colletti L, Fiorino F. Auditory Brainstem Implant (ABI): New Frontiers in Adults and Children, Otolaryngology - Head and Neck Surgery 2005, 133(1):126-138. PMID: 16025066

17. Kaplan AB., Kozin ED, Puram SV, Owoc MS, Shah PV, Hight AE, Sethi RKV, Remenschneider AK, Lee DJ. Auditory Brainstem Implant Candidacy in the United States in Children 0-17 Years Old. International Journal of Pediatric Otorhinolaryngology. 2015; 79(3): 310-315. PMID: 25577282 


\section{FIGURES}

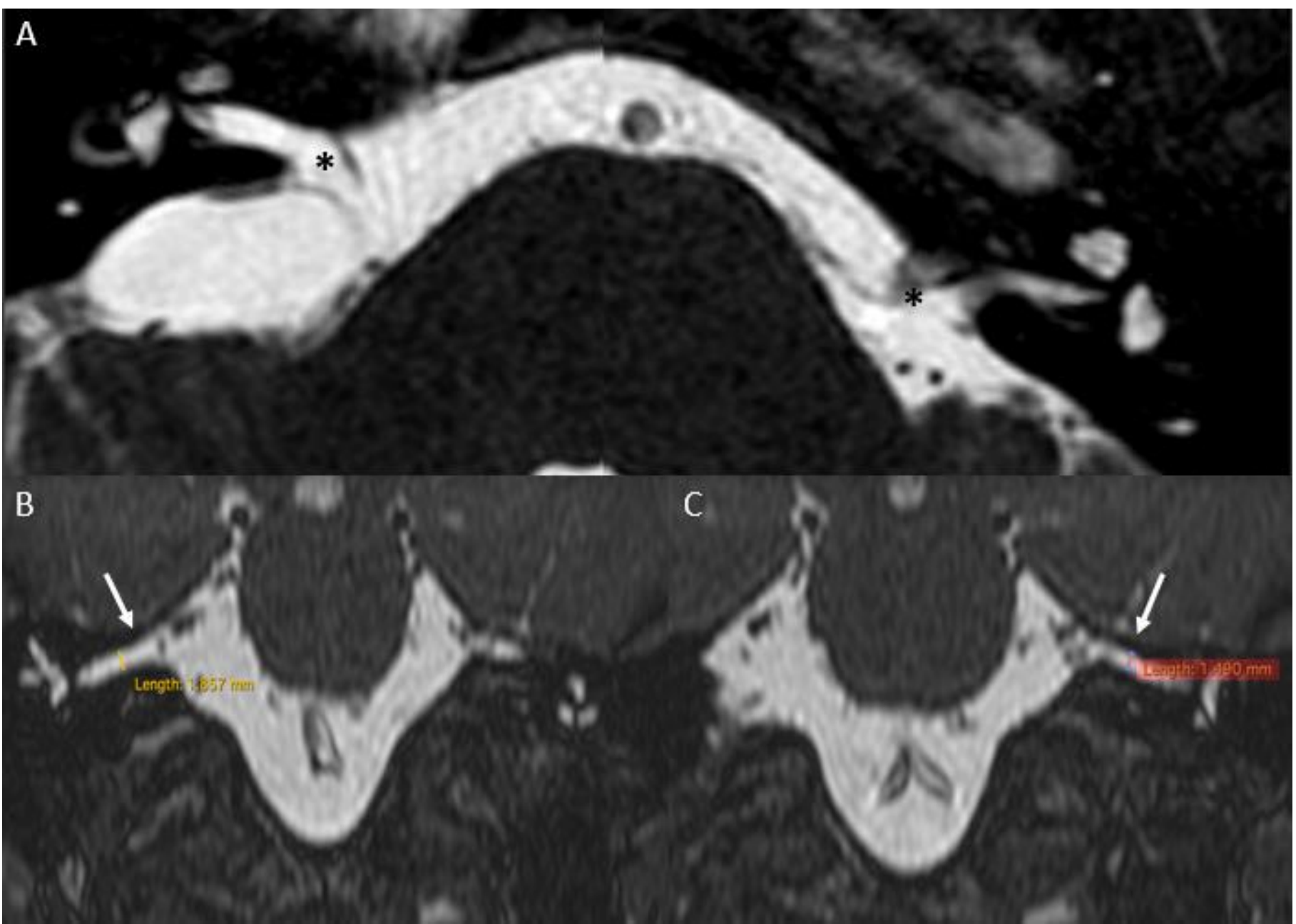

Figure 1: A 6-year-old male presented with marked bilateral congenital sensorineural hearing loss.

Findings: MRI brain performed on initial diagnosis. Non-contrast axial (A) and coronal (B and C) fast imaging employing steady-state acquisition (FIESTA) shows no vestibulocochlear nerves (black asterisks in A) and bilateral stenosis of the IAC, left (white arrow in C) greater than right (white arrow in B).

Technique: MRI, Philips 1.5-Tesla; Axial fast imaging employing steady-state acquisition (FIESTA): TR 6.9875, TE: 1.000. 


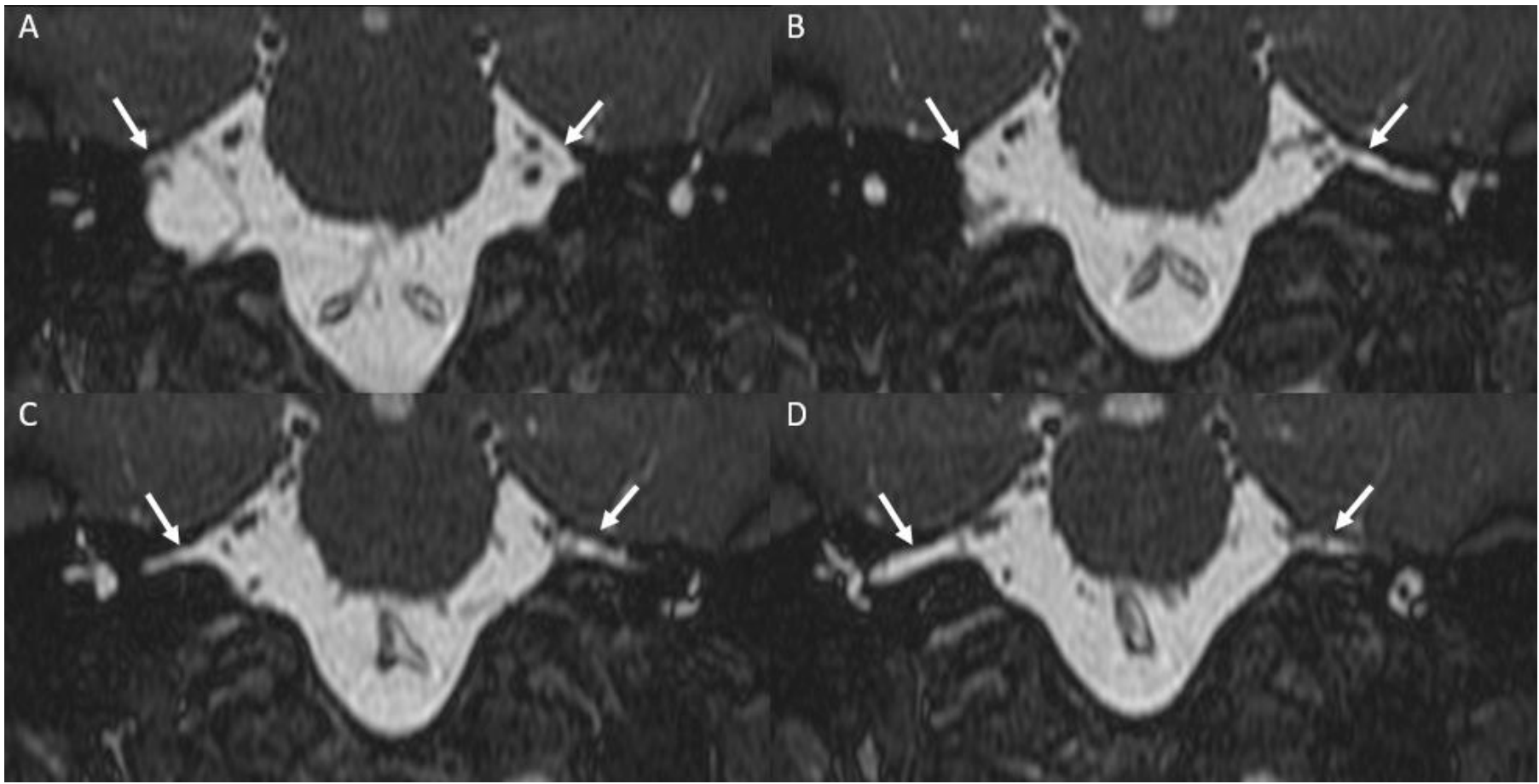

Figure 2: A 6-year-old male presented with marked bilateral congenital sensorineural hearing loss.

Findings: MRI brain performed on initial diagnosis. Non-contrast sequential coronal images through the internal auditory canals (IAC) using fast imaging employing steady-state acquisition (FIESTA) shows vessel structures in close anatomical relationship with the ICAs but no evidence of vestibulocochlear nerves (white arrows in A, B, C and D).

Technique: MRI, Philips 1.5-Tesla; Axial fast imaging employing steady-state acquisition (FIESTA): TR 6.9875, TE: 1.000.

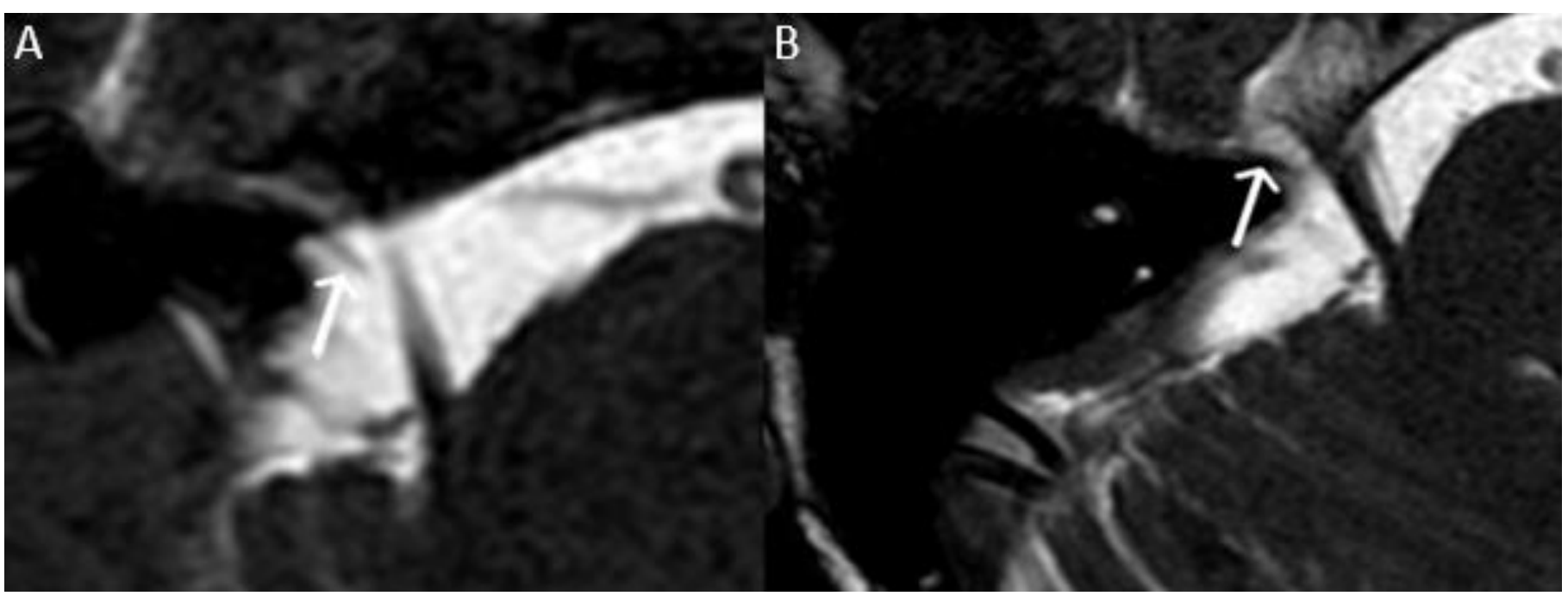

Figure 3: A 6-year-old male presented with marked bilateral congenital sensorineural hearing loss.

Findings: MRI brain performed on initial diagnosis. Non-contrast axial fast imaging employing steady-state acquisition (FIESTA) shows the facial nerve's aberrant course in its cisternal segment (white arrow in A). and the minute facial nerve canal (white arrow in B).

Technique: MRI, Philips 1.5-Tesla; Axial fast imaging employing steady-state acquisition (FIESTA): TR 6.9875, TE: 1.000. 


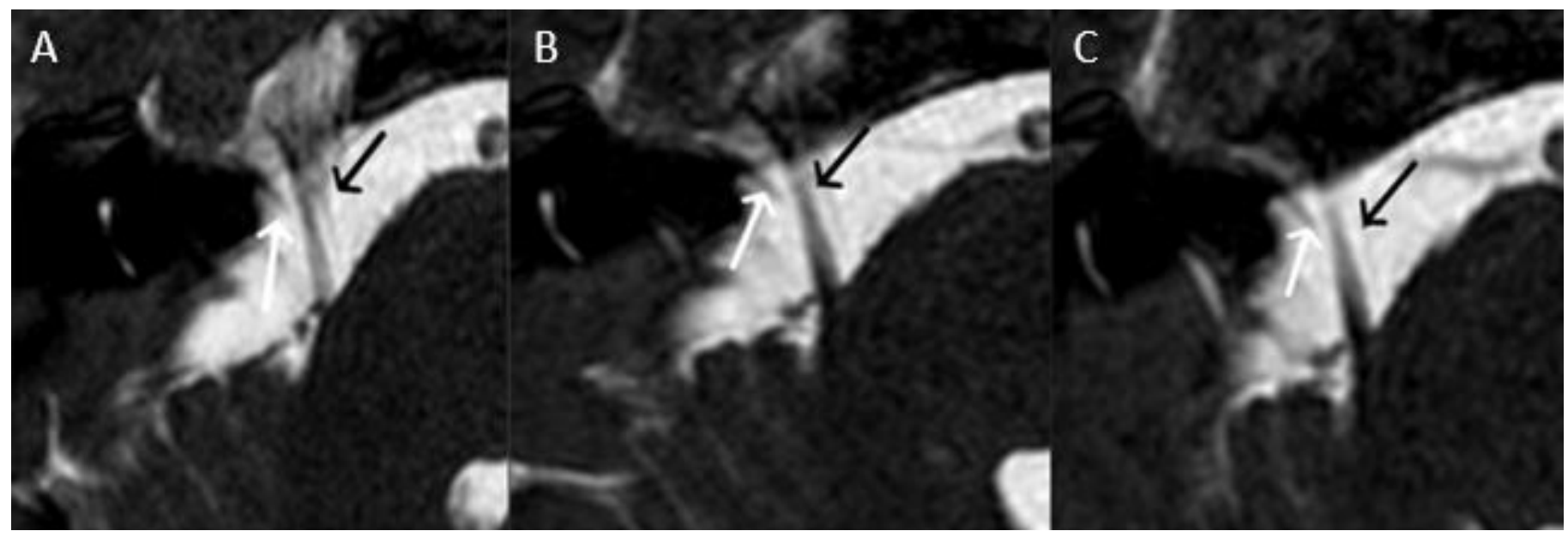

Figure 4: A 6-year-old male presented with marked bilateral congenital sensorineural hearing loss.

Findings: MRI brain performed on initial diagnosis. Non-contrast axial fast imaging employing steady-state acquisition (FIESTA) shows the facial nerve (white arrows in A, B and C) running below the trigeminal nerve (black arrows in A, B and C) towards the Gasserian ganglion. The facial nerve takes a sharp turn into a minute canal (white asterisks in A, B and C).

Technique: MRI, Philips 1.5-Tesla; Axial fast imaging employing steady-state acquisition (FIESTA): TR 6.9875, TE: 1.000.

\begin{tabular}{|l|l|}
\hline Etiology & Congenital \\
\hline Incidence & The aberrant facial nerve is a rare abnormality found in patients with congenital anomaly of the middle ear \\
\hline Age predilection & Congenital malformation \\
\hline Risk factors & Hypoplasia of the internal auditory canal and agenesis of the vestibulocochlear nerve \\
\hline Treatment & Surgical treatment in selected cases \\
\hline Symptoms & Most patients with facial nerve anomaly do not have clinical symptoms \\
\hline Imaging Findings & $\begin{array}{l}\text { The facial nerve runs beneath the trigeminal nerve towards the Gasserian ganglion and takes a sharp turn to } \\
\text { the side into a minute canal }\end{array}$ \\
\hline
\end{tabular}

Table 1: Summary table of aberrant intracranial course of the facial nerve.

\begin{tabular}{|l|l|}
\hline Diagnoses & MRI \\
\hline Moebius syndrome & $\begin{array}{l}\text { The sixth and seventh nerve nuclei are absent, as seen by flattening of the fourth ventricle and pontine } \\
\text { hypoplasia. There may be cerebellar hypoplasia, calcification of pons in the region of abducens nerve, } \\
\text { and absence of middle cerebellar peduncles. }\end{array}$ \\
\hline $\begin{array}{l}\text { Aberrant facial } \\
\text { nerve canal }\end{array}$ & $\begin{array}{l}\text { It arises inferiorly and laterally from Meckel's cave, then courses through the petrous bone to the IAC } \\
\text { fundus. There is normal morphology of the remaining labyrinthine, tympanic, and descending mastoid } \\
\text { facial nerve segments. }\end{array}$ \\
\hline $\begin{array}{l}\text { Hypoplastic facial } \\
\text { nerve canal }\end{array}$ & $\begin{array}{l}\text { The labyrinthine facial nerve is reduced in caliber. It may be isolated or associated with hypoplasia of } \\
\text { the other segments, and it can be often seen in inner ear dysplasia. }\end{array}$ \\
\hline $\begin{array}{l}\text { Aberrant course of } \\
\text { the facial nerve }\end{array}$ & $\begin{array}{l}\text { The facial nerve runs beneath the trigeminal nerve towards the Gasserian ganglion and takes a sharp turn } \\
\text { to the side into a minute canal }\end{array}$ \\
\hline
\end{tabular}

Table 2: Differential diagnosis table for aberrant intracranial course of the facial nerve. 


\section{ABBREVIATIONS}

$\mathrm{CT}=$ Computer Tomography

FN $=$ Facial Nerve

IAC $=$ Internal Auditory Canal

MRI = Magnetic Resonance Imaging

SNHL $=$ Sensorineural Hearing Loss

$\mathrm{VCN}=$ Vestibulocochlear nerve

\section{KEYWORDS}

Magnetic Resonance Imaging; Vestibulocochlear Nerve Agenesis; Aberrant Facial Nerve; Sensorineural Hearing Loss; Internal Auditory Canal Atresia

\section{ACKNOWLEDGMENTS}

The authors would like to thank Dr. Sacha Baldeosingh (Johns Hopkins, Baltimore) for the revision of the text in English.

\section{Online access}

This publication is online available at:

www.radiologycases.com/index.php/radiologycases/article/view/3912

\section{Peer discussion}

Discuss this manuscript in our protected discussion forum at: www.radiolopolis.com/forums/JRCR

\section{Interactivity}

This publication is available as an interactive article with scroll, window/level, magnify and more features.

Available online at www.RadiologyCases.com

\section{Published by EduRad}

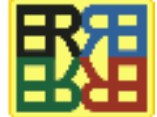

www.EduRad.org 